Article

\title{
Study of Texture Analysis on Asymmetric Cryorolled and Annealed CoCrNi Medium Entropy Alloy
}

\author{
Yuze $\mathrm{Wu}^{1,2,3}$, Juan Liu ${ }^{1,2,3}$, Laxman Bhatta ${ }^{1,2,3} \mathbb{C}$, Charlie Kong ${ }^{4}$ and Hailiang $\mathrm{Yu}^{1,2,3, * \mathbb{C}}$ \\ 1 State Key Laboratory of High Performance Complex Manufacturing, Central South University, \\ Changsha 410083, China; wyz2019@csu.edu.cn (Y.W.); lj2019@csu.edu.cn (J.L.); \\ bhattalaxman99@gmail.com (L.B.) \\ 2 Light Alloys Research Institute, Central South University, Changsha 410083, China \\ 3 College of Mechanical and Electrical Engineering, Central South University, Changsha 410083, China \\ 4 Mark Wainwright Analytical Centre, University of New South Wales, Sydney, NSW 2052, Australia; \\ c.kong@unsw.edu.au \\ * Correspondence: yuhailiang@csu.edu.cn
}

Received: 11 November 2020; Accepted: 15 December 2020; Published: 18 December 2020

\begin{abstract}
CoCrNi}$ equiatomic medium entropy alloy sheets were prepared by asymmetric rolling, cryorolling, and asymmetric cryorolling. The asymmetric cryorolled samples exhibited a noteworthy ultra-fine-grain heterogeneous lamella structure. The microstructure and corresponding hardness obtained by different rolling processes and subsequent annealing are compared. It can be seen from the results that the cryogenic deformation temperature had a stronger effect on the mechanical properties of the medium entropy alloys (MEA), compared with the shear strain caused by the asymmetric cryorolling. The effect of annealing temperature on texture components and volume fractions of the specially rolled samples was also analyzed. The result revealed that the recrystallized MEA exhibited similar texture components and the corresponding volume fraction, which indicated that the rolling process had limited influence on the formation of annealing texture. The recrystallized texture after annealing retained the deformation texture and twin related orientations appeared. Asymmetric rolled MEA showed strong random composition than symmetric rolled MEA regardless of rolling temperature. The recrystallized textures of the species obtained by the three rolling processes did not exhibit a significant dependence on the annealing temperature.
\end{abstract}

Keywords: $\mathrm{CrCoNi}$ alloy; medium entropy alloy; thermomechanical processing; texture; heterogeneous structure; asymmetrical cryorolling

\section{Introduction}

High entropy alloys (HEAs) are a popular direction for the current development of material science, which have many unique structures and characteristics due to their special composition. The HEAs have been found to have many excellent properties that exceed traditional alloys, such as high hardness [1], high strength [2-6], high plasticity, high toughness [7,8], high fatigue resistance [9], strong corrosion resistance [10], strong radiation resistance [11], and ultra-high tensile properties and plasticity at cryogenic temperatures [12]. They have great potential to replace and upgrade current industrial alloys and are the development direction of future materials. Medium entropy alloys (MEAs) are based on the concept of high entropy alloys, a new type of multi-component alloy with three or four principal elements as the characteristics and mixing entropy of $1 R$ or $1.5 R$ [13]. While having the distinguished properties of high entropy alloys (the lattice distortion effect; sluggish diffusion [14,15]), medium entropy alloys also perform excellent even better mechanical properties. In the comparison of the properties of the equiatomic medium entropy alloys and the high entropy alloys, the ternary 
equiatomic middle entropy alloy $\mathrm{CoCrNi}$ was found to have the highest strength. Interestingly, it also has the highest plasticity, and it stably exhibits such advantageous performance in a wide range of test temperatures [16]. Likewise, Laplanche et al. [17] found that there were more nano twins in the deformation process of equiatomic $\mathrm{CoCrNi}$ MEA compared with the classical equiatomic high entropy alloy $\mathrm{CoCrNiFeMn}$. The existence of deformation twins in an extended strain range imparted a good strength-ductility synergy [17]. The equiatomic medium entropy $\mathrm{CoCrNi}$ alloy has become a new interest in the research of medium entropy alloys because of its simple, stable crystal structure and excellent mechanical properties. However, the current research mainly focuses on the evolution of the recrystallized structure of MEA after plastic deformation $[18,19]$ and the influence of nano twins on the properties of alloy $[17,20-24]$. Nevertheless, considering the actual investment in industrial production applications, it is necessary to further study the changes in the microstructure and texture of the alloy during plastic deformation and recrystallization during mechanical processing.

As an interesting thermo-mechanical processing (TMP) route, cryorolling can bring obvious grain refinement and improve materials properties by inhibiting the dynamic recovery and improving the twinning activity during the deformation process. Asymmetric cryorolling can introduce more shear strain to bring better thinning effect $[25,26]$. These researches mainly focus on some traditional alloys [27-31], and there are few studies on HEAs or MEAs. It is meaningful to combine the two process to study whether there will be more interesting coupling reactions. In the previous work [32,33], we found that the rolling speed ratio $\left(1.2,1.4\right.$, and 1.6) and cryogenic temperature $\left(-190^{\circ} \mathrm{C}\right)$ could have an obvious impact on the performance of the equiatomic medium entropy alloy $\mathrm{CoCrNi}$, especially when the rolling speed ratio is 1.4, compared with the ordinary rolling process, the MEA obtained by asymmetric cryorolling had an obvious performance improvement effect, and the strength and plasticity are improved at the same time. These results show that asymmetric cryorolling is very suitable for producing higher-performance MEAs, and it is also meaningful to analyze the crystal texture of the material obtained by this TMP route. Therefore, we chose the asymmetric cryorolling with the rolling speed ratio of 1.4 and compared it with cryorolling and asymmetric rolling. The reason for choosing 1.4 here is because it is more typical compared to rolling speed ratio of 1.2 (relatively low) or 1.6 (relatively high) and can better representing the deformation features of asymmetric rolling. At the same time, it showed excellent mechanical properties when the rolling speed ratio is 1.4, and it is more valuable to study it. In the paper, we studied the evolution of texture components, strength, volume fractions and corresponding microstructure with the different temperatures annealing. It was aimed to further understand the MEAs produced by these special processes and to fill the gaps in texture research of the asymmetric cryorolled CoCrNi MEAs.

\section{Experimental}

The experimental equiatomic $\mathrm{CrCoNi}$ alloy ingots were prepared by vacuum arc melting and the test specimens for rolling were prepared by wire cutting. The initial thickness of the specimen was $1 \mathrm{~mm}$. These sheets were asymmetrically rolled (room temperature, rolling speed ratio of 1.4), cryorolled $\left(-196^{\circ} \mathrm{C}\right)$, and asymmetric cryorolled $\left(-196^{\circ} \mathrm{C}\right.$, rolling speed ratio of 1.4$)$ to a final thickness of $0.2 \mathrm{~mm}$ in 9 passes. To maintain cryogenic temperatures during the cryorolling and asymmetric cryorolling, the samples were immersed in liquid nitrogen for more than $10 \mathrm{~min}$ before each rolling pass. These rolled samples were then isochronally annealed at $600{ }^{\circ} \mathrm{C}, 700^{\circ} \mathrm{C}$, and $800^{\circ} \mathrm{C}$ for $30 \mathrm{~min}$.

The microstructure and texture were characterized by using an electron backscatter diffraction (EBSD) system (Oxford Instruments, Nordlys, Abingdon, Oxfordshire, UK) at Institute of Metal Research (China Academy of Sciences, Shenyang, Liaoning, China). The samples for EBSD observations were mechanically polished and then were ion-etched using a Leica RES101 ion-etcher (Leica Microsystems, Ernst-Leitz-Strasse, Wetzlar, Germany). The step size for the EBSD measurements was $0.0754 \mu \mathrm{m}$. The EBSD tests were taken from the ND-RD plane close to the center of the deformed specimens to reveal the microstructure. The orientation distribution function (ODF) in this paper illustrated the TD-RD section of the samples processed at different rolling conditions and annealing temperatures. 
The acquired EBSD results were analyzed using the HKL Channel 5 Software. The texture volume fractions were calculated by the texture component function, the volume fraction of individual texture components was calculated using a spread of $10^{\circ}$ from their ideal orientation.

Micro-hardness tests were performed on the HXD-2000TMC/LCD (Taiming, Shanghai, China) digital micro-hardness tester with a load of $4.903 \mathrm{~N}$ and a retention time of $10 \mathrm{~s}$. Five evenly distributed locations were selected on each sample for measurement to ensure accurate experimental results. The variance of each group of data was calculated to obtain the final hardness value.

\section{Results and Discussion}

Figure 1 shows the coincidence site lattice (CSL) grain boundary (GB) diagrams of the asymmetric rolled, cryorolled, and asymmetric cryorolled equiatomic medium entropy $\mathrm{CoCrNi}$ alloy. Figure 1a,c,e depicts the CSL grain boundary after annealing at $600^{\circ} \mathrm{C}$, and Figure $1 \mathrm{~b}, \mathrm{~d}, \mathrm{f}$ represents the CSL grain boundary after annealing at $800^{\circ} \mathrm{C}$. Red, green, purple, yellow, and pink lines correspond to $\sum 3, \sum 5$, $\sum 9, \sum 11$, and $\sum 27$ boundaries, respectively. It is evident from Figure 1 that a high proportion of $\sum 3$ boundaries, while few $\sum 9, \sum 27, \sum 5, \sum 11$ boundaries and other special grain boundaries were observed in all the samples. It could be seen that asymmetric rolled CoCrNi MEA samples have obvious coarse-grained and fine-grained layer structures, and cryorolled CoCrNi MEA samples have a finer microstructure. The stacking fault energy of CoCrNi medium entropy alloy is very low, even lower than that of $\mathrm{CrMnFeCoNi}$ high entropy alloy, which promotes a high tendency to produce $\sum 3$ twin boundaries $[17,34,35]$. Correspondingly, a large number of red $\sum 3$ grain boundaries were observed in Figure 1. Meanwhile, it is worth mentioning that most of the $\sum 3$ grain boundaries in the CoCrNi MEA annealed at $600{ }^{\circ} \mathrm{C}$ were curved. While in the CoCrNi MEA annealing at $800{ }^{\circ} \mathrm{C}$, the degree of recrystallization was further increased, at this time, the $\sum 3$ grain boundaries were generally straight, which is consistent with the change after annealing of $\mathrm{CoCrFeNiMn}$ high entropy alloy observed by Tang et al. [36]. Furthermore, the research of Thomson et al. [37] revealed that as the annealing progress, the degree of recrystallization increases, and the curved incoherent $\sum 3$ grain boundaries would be transformed into straight coherent $\sum 3$ grain boundaries through fine tuning. The curved $\sum 3$ twin boundary is a mobile incoherent grain boundary, and would react with other grain boundaries during this process. The $\sum 9$ grain boundaries could be formed by the twinning reaction of the incoherent $\sum 3$ grain boundaries when impinged with each other, as a result, a relatively large number of $\sum 9$ boundaries were observed in the $600{ }^{\circ} \mathrm{C} \mathrm{CoCrNi} \mathrm{MEA}$, as illustrated in Figure 1a,c,e. According to the theory of ' $\sum 3$ regeneration model', the impingement of $\sum 3$ and $\sum 9$ is more inclined to generate $\sum 3$ grain boundaries rather than $\sum 27$ grain boundaries for $\mathrm{CoCrNi}$ medium entropy alloys with low stacking fault energy and greater mobility. Consequently, a large number of $\sum 3$ grain boundaries were still observed in the samples annealed at $800{ }^{\circ} \mathrm{C}$ [38]. At the same time, this also explain the phenomenon of less $\sum 9$ ratio observed in Figure $1 \mathrm{~b}, \mathrm{~d}, \mathrm{f}$ after annealing at higher temperature, which is also consistent with the phenomenon observed by Dan Sathiaraj et al. [39].

Figure 2 depicts the corresponding grain size distribution of the equiatomic CoCrNi MEA after asymmetric rolling, cryorolling, and asymmetric cryorolling followed by annealing. It could be seen that the majority of the grain sizes are sub-micron level, mainly distribute in the range of $0-0.25 \mu \mathrm{m}$. The grain size distribution after annealing at $600^{\circ} \mathrm{C}$ is mainly in the range of $0-6.25 \mu \mathrm{m}$ (Figure 2a,c,e) compared to that of $0-9.75 \mu \mathrm{m}$ after annealing at $800^{\circ} \mathrm{C}$ (Figure $2 \mathrm{~b}, \mathrm{~d}, \mathrm{f}$ ) which exhibits obvious grain coarsening. It is evident from Figure 2 that the overall average grain size is in the micron range and has an ultra-fine grain structure. This result may be attributed to the sluggish diffusion characteristics of the high entropy alloys [40] and the fine microstructure in the rolled CoCrNi MEA before annealing. As shown in Figure 2a,b, large-scale grains of 5.75-6.25 $\mu \mathrm{m}$ and 9.25-9.75 $\mu \mathrm{m}$ appeared in the room temperature asymmetrically rolling MEAs annealed at $600^{\circ} \mathrm{C}$ and $800{ }^{\circ} \mathrm{C}$, respectively. This result indicates that asymmetric rolling is feasible for producing heterogeneous lamellar structure. As shown in Figure 2c,d, the upper limit of grain distribution of the cryogenic symmetrically rolled CoCrNi MEA annealed at $600^{\circ} \mathrm{C}$ and $800^{\circ} \mathrm{C}(4.75 \mu \mathrm{m}, 5.75 \mu \mathrm{m})$ was significantly smaller than that of asymmetrically 
rolled at room temperature $(6.25 \mu \mathrm{m}, 9.75 \mu \mathrm{m})$. Meanwhile, the proportion of ultra-fine grain size $(0-0.25 \mu \mathrm{m})$ of the two was nearly the same, and the overall average grain size of the cryogenic symmetrically rolled and annealed CoCrNi MEA was less, which verified the better effect of cryogenic rolling on grain refinement. As shown in Figure 2e,f, the CoCrNi MEA of asymmetric cryorolling had the smallest upper limit of grain size distribution at $600{ }^{\circ} \mathrm{C}$, large-scale grains of $8.75-9.25 \mu \mathrm{m}$ were observed after annealing at $800^{\circ} \mathrm{C}$. As shown in Figure $1 \mathrm{~b}, \mathrm{f}$, the large-scale grains of asymmetric cryorolling was smaller than of asymmetric rolling. In addition, it can be obviously observed that the size of the small-grain of the asymmetric cryorolled CoCrNi MEA annealed at $800{ }^{\circ} \mathrm{C}$ was finer, compared with the MEAs obtained by other two processes (Figure 1b,d,f). This indicated that that the asymmetric cryorolling process could bring obvious grain refinement, while still maintaining the obvious difference in coarse and fine grains of the asymmetric rolling.

Rolled and $600{ }^{\circ} \mathrm{C}$ Annealing, $0.5 \mathrm{~h}$

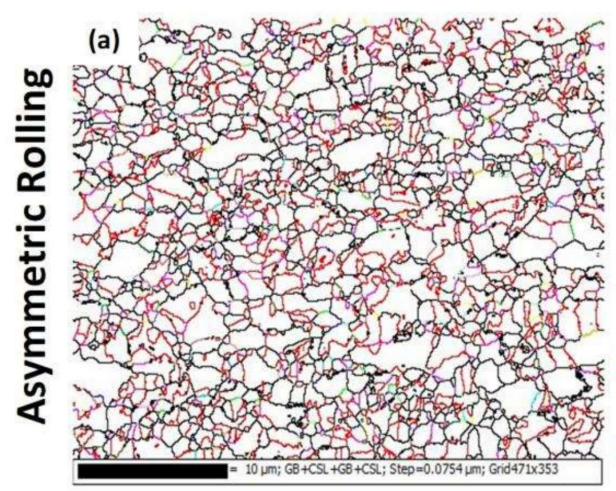

(c)
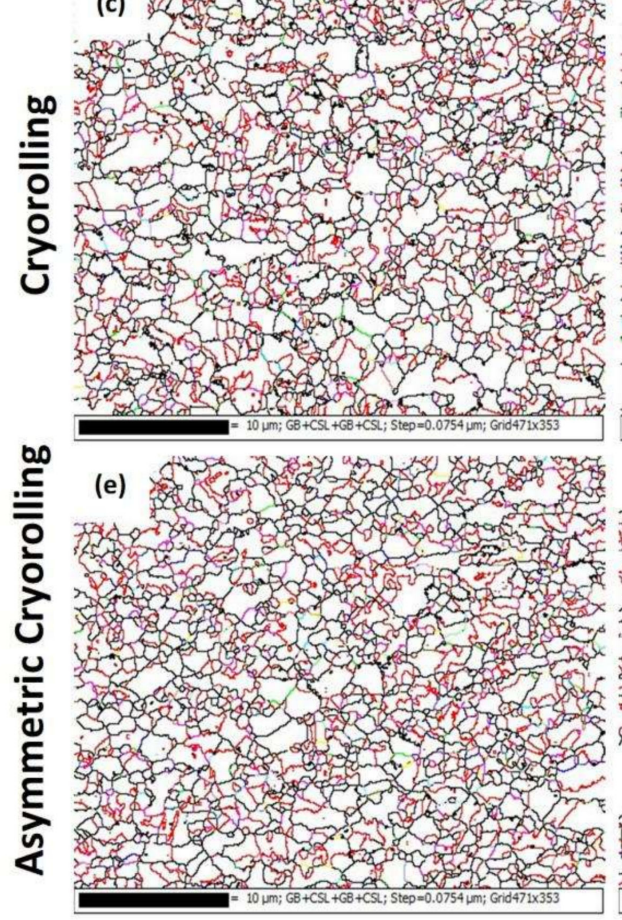

Rolled and $800{ }^{\circ} \mathrm{C}$ Annealing, $0.5 \mathrm{~h}$

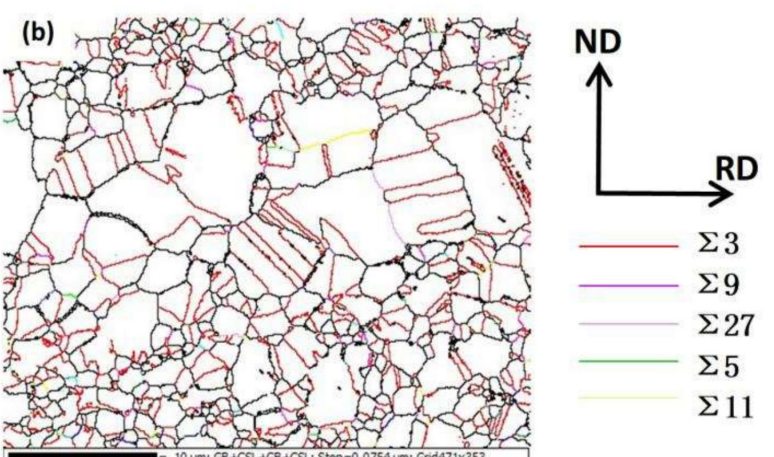

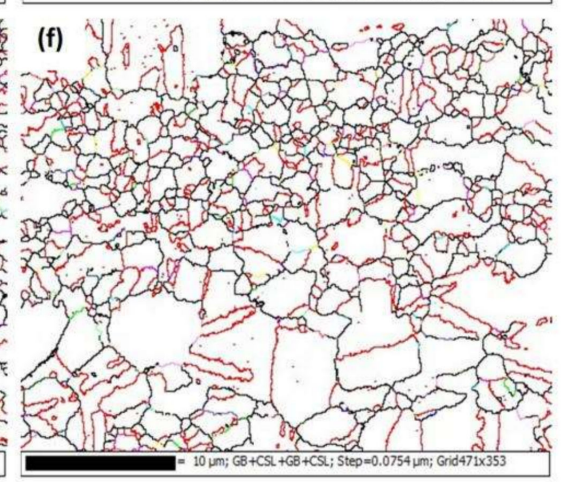

Figure 1. Coincidence site lattice (CSL) GB maps of (a) asymmetrically rolled medium entropy alloys (MEA) $\mathrm{CrCoNi}$ with annealing at $600{ }^{\circ} \mathrm{C},($ b) asymmetrically rolled MEA CrCoNi with annealing at $800{ }^{\circ} \mathrm{C},(\mathbf{c})$ cryorolled MEA CrCoNi with annealing at $600{ }^{\circ} \mathrm{C},(\mathrm{d})$ cryorolled MEA CrCoNi with annealing at $800^{\circ} \mathrm{C}$, (e) asymmetric cryorolled MEA $\mathrm{CrCoNi}$ with annealing at $600^{\circ} \mathrm{C}$, and (f) asymmetric cryorolled MEA CrCoNi with annealing at $800^{\circ} \mathrm{C}$. 

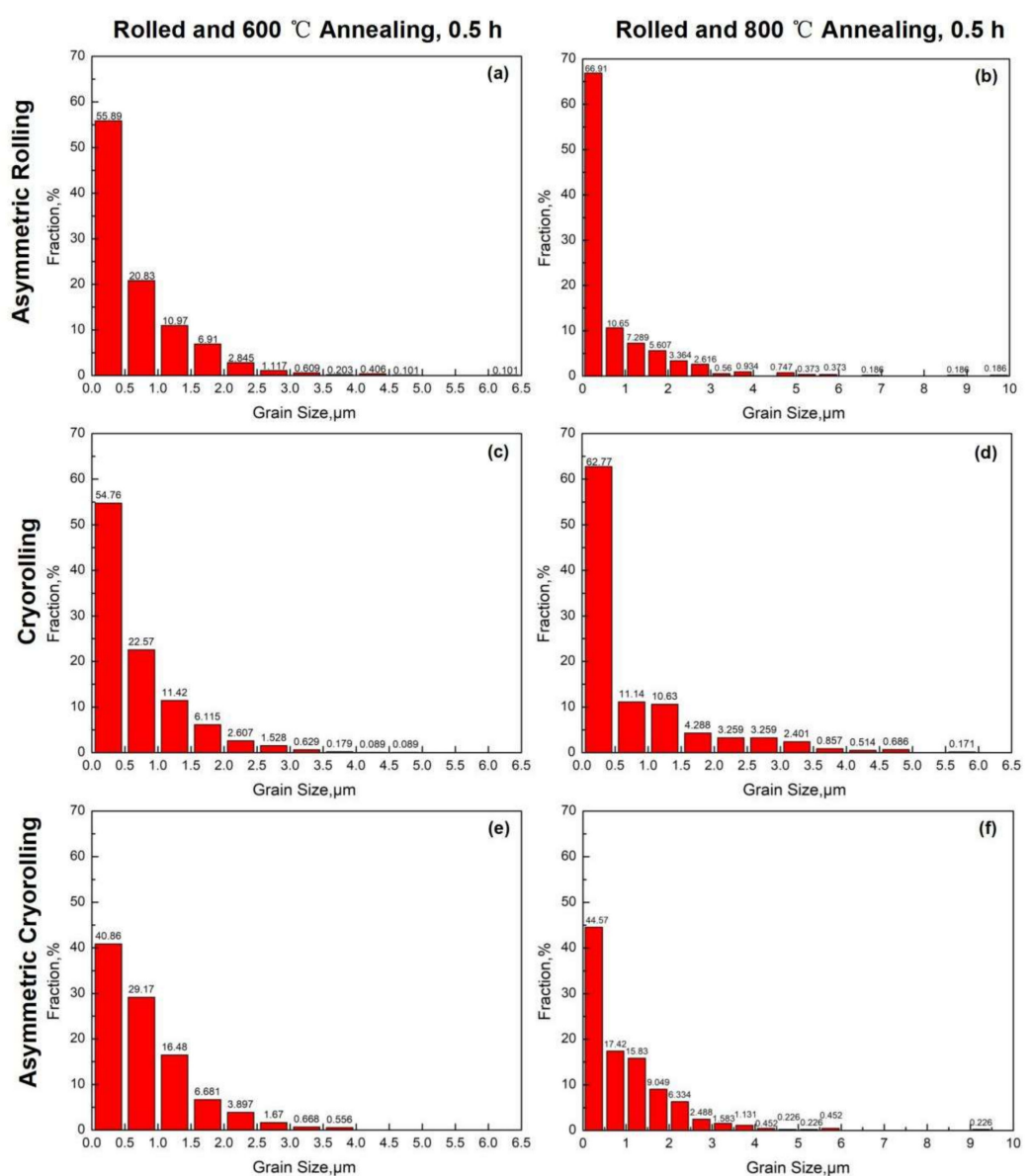

Figure 2. Grain size distribution of (a) asymmetrically rolled MEA $\mathrm{CrCoNi}$ with annealing at $600{ }^{\circ} \mathrm{C}$, (b) asymmetrically rolled MEA CrCoNi with annealing at $800^{\circ} \mathrm{C},(\mathrm{c})$ cryorolled MEA CrCoNi with annealing at $600^{\circ} \mathrm{C},(\mathbf{d})$ cryorolled MEA CrCoNi with annealing at $800^{\circ} \mathrm{C}$, (e) asymmetric cryorolled MEA CrCoNi with annealing at $600^{\circ} \mathrm{C}$, and (f) asymmetric cryorolled MEA CrCoNi with annealing at $800{ }^{\circ} \mathrm{C}$.

Figure 3 depicts the orientation distribution function (ODF) sections of the CoCrNi MEA after asymmetric rolling, cryorolling, asymmetric cryorolling followed by subsequent annealing, displaying important recrystallization texture components and $\alpha$-fiber observed in the CoCrNi MEA. Their corresponding Euler angles and Miller indices are given in Table 1. The ODF in Figure 4 illustrates the TD-RD section of the samples processed at different rolling conditions and annealing temperatures. The $\phi_{2}=0^{\circ} \mathrm{ODF}$ sections of the CoCrNi MEA after annealing at $600{ }^{\circ} \mathrm{C}$ (Figure $4 \mathrm{a}, \mathrm{c}, \mathrm{e}$ ) exhibited the development of a weak and discontinuous $\alpha-\{110\}$ fiber extending from the $\{110\}<001>$ Goss to the $\{110\}<110>$ Rotated Goss through the $\{110\}<115>\mathrm{G} / \mathrm{B},\{110\}<112>$ Brass, and $\{110\}<111>$ A orientations. The A component is the first order twin related to $G / B$ [39]. $\alpha-\{110\}$ fiber texture was also observed in the samples annealed at $800^{\circ} \mathrm{C}$ and showed the maximum intensity located near $\{110\}<115>\mathrm{G} / \mathrm{B}$ and $\{110\}<111>$ A. Obvious retention of deformation texture was observed. A number of previous studies on the five-element CoCrFeNiMn high entropy alloy and the quaternary CrFeCoNi medium entropy alloy also displayed the existence of deformation texture in the recrystallization texture [41-44]. The retention of deformation texture usually occurs in case of prolonged recovery or primary or discontinuous recrystallization without any preferential orientation selection. Based on the softening mechanism of HEAs [42], the extended recovery is ruled out, so this phenomenon was explained by the discontinuous recrystallization mechanics without preferential orientation selection [43]. A similar trend of retention of deformation texture after annealing was observed in twinning-induced-plasticity (TWIP) steels. The micro shear bands in the deformed materials of both had no significant contribution 
to the preferential nucleation analysis $[41,43]$. The presence of the relatively strong $\{110\}<111>A$ component corresponded to the large number of $\sum 3$ twin boundaries in Figure 1. Furthermore, the low stacking fault energy (SFE) of CoCrNi MEA could lead to numerous annealing twins, which in turn enhances the formation of the $\{110\}<111>$ A component $[43,45]$. The BS orientation was weak due to the slower recrystallization kinetics of the BS orientation region. During the recrystallization process, the region near BS orientation was gradually replaced by adjacent recrystallized grains due to the slower recrystallization rate [43]. The $\{142\}<211>\mathrm{K}$ component was observed in the $\phi_{2}=15^{\circ}$ ODF sections and the corresponding strength of $\mathrm{K}$ component increased with increasing annealing temperature from $600{ }^{\circ} \mathrm{C}$ to $800^{\circ} \mathrm{C}$. The typical brass recrystallization (BR) $\{236\}<385>$ BR component was observed in the $\phi_{2}=35^{\circ}$ sections. In low SFE alloys such as brass, there is often a strong BR component after annealing due to the nucleation at shear bands and subsequent preferential growth [46]. However, at $\phi_{1}, \phi, \phi_{2}=80^{\circ}, 31^{\circ}, 35^{\circ}$ sections, no obviously strong BR component was observed. The BR component was relatively weak, there is less tendency to preferential nucleation in HEAs, which corresponds to the retention of the deformation texture in the $\phi_{2}=0^{\circ}$ sections. This phenomenon is similar to that observed in other annealed HEAs and MEAs $[39,42,43,47]$. In the $\phi_{2}=45^{\circ}$ sections, strong $\{113\}<332>\mathrm{D}$ component was observed nearby $\phi_{1}, \phi, \phi_{2}=90^{\circ}, 25^{\circ}, 45^{\circ}$. The $\alpha$-fiber twin related texture components were observed. While D and $\mathrm{K}$ components have first order twin relation with G [32]. \{123\}<634>S component and strong $\{13625\}<201514>$ M component were visible in the $\phi_{2}=65^{\circ}$ sections. The parameters of the ideal texture components referred above are derived from $[39,41,42]$. The texture composition of the asymmetric rolled, cryorolled, and asymmetric cryorolled CoCrNi MEAs followed by subsequent annealing did not show significant change with annealing temperature. Similar behavior was also observed in the studies of symmetric rolling in previous reports of HEAs and MEAs. It might could attribute to the effect of sluggish diffusion of the HEAs, which could also lead to higher fraction of random components in HEAs $[39,41-44,48]$.

Previous studies on texture have reported that process parameters such as imposed strain, strain path, annealing temperature have a relatively great impact on the recrystallization texture of FCC metals [49]. However, in the present study, although the rolling process enhanced the microstructure and mechanical properties of CoCrNi medium entropy alloy significantly, the CoCrNi MEA that underwent annealing and recrystallization formed a similar texture composition. This should be due to the absence of obvious preferential nucleation and preferential growth during annealing. Similar situations have been reported in other HEA studies. When the mechanical properties and structure of the equiatomic CoCrFeMnNi high entropy alloy after rolling with different strains were different, the recrystallization texture of the alloys showed similar recrystallization texture [42].

Table 1. Important recrystallization texture components in the CoCrNi MEA.

\begin{tabular}{cccc}
\hline Texture Component & Symbol & Euler Angle & Miller Indices \\
\hline Cube $(\mathrm{C})$ & - & $0,0,0$ & $\{001\}<100>$ \\
\hline Copper(Cu) & $\times$ & $90,35,45$ & $\{112\}<111>$ \\
\hline Goss(G) & $\bullet$ & $0,45,0$ & $\{110\}<001>$ \\
\hline Brass(Bs) & $\bullet$ & $35,45,0$ & $\{110\}<112>$ \\
\hline S & $\square$ & $59,37,63$ & $\{123\}<634>$ \\
\hline G/B & $\bullet$ & $17,45,0$ & $\{110\}<115>$ \\
\hline A & $\bullet$ & $55,45,0$ & $\{110\}<111>$ \\
\hline Rotated Goss(Rt-G) & $\star$ & $90,45,0$ & $\{110\}<110>$ \\
\hline BR & $\bullet$ & $80,31,35$ & $\{236\}<385>$ \\
\hline M & $\diamond$ & $80,30,65$ & $\{13625\}<201514>$ \\
\hline D & $*$ & $90,25,45$ & $\{113\}<332>$ \\
\hline K & $\oplus$ & $27,64,14$ & $\{142\}<211>$ \\
\hline
\end{tabular}




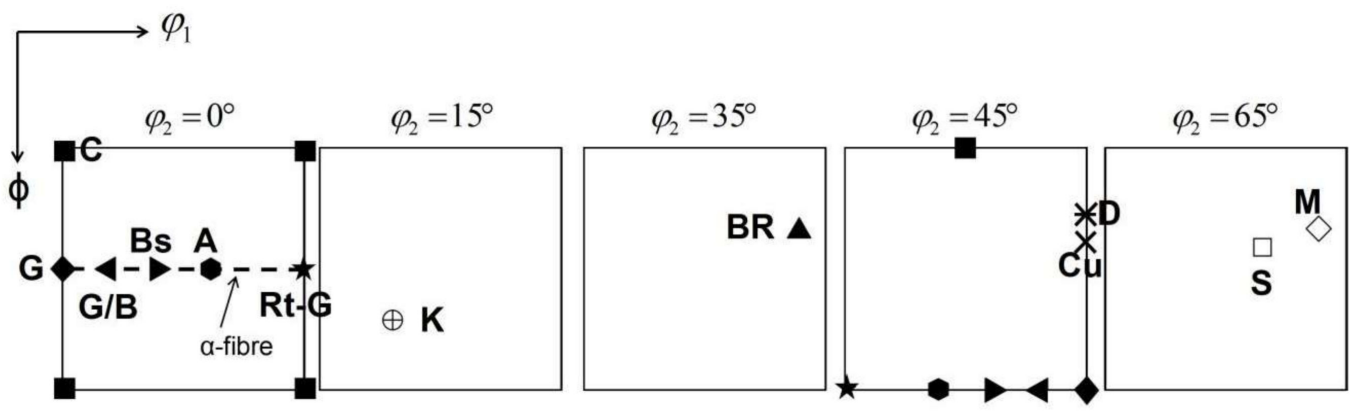

Figure 3. Schematic representation of important recrystallization texture components and $\alpha$-fiber observed in the CoCrNi MEA, orientation distribution function (ODF) sections at $\phi_{2}=0^{\circ}, 15^{\circ}, 35^{\circ}, 45^{\circ}$, and $65^{\circ}$.
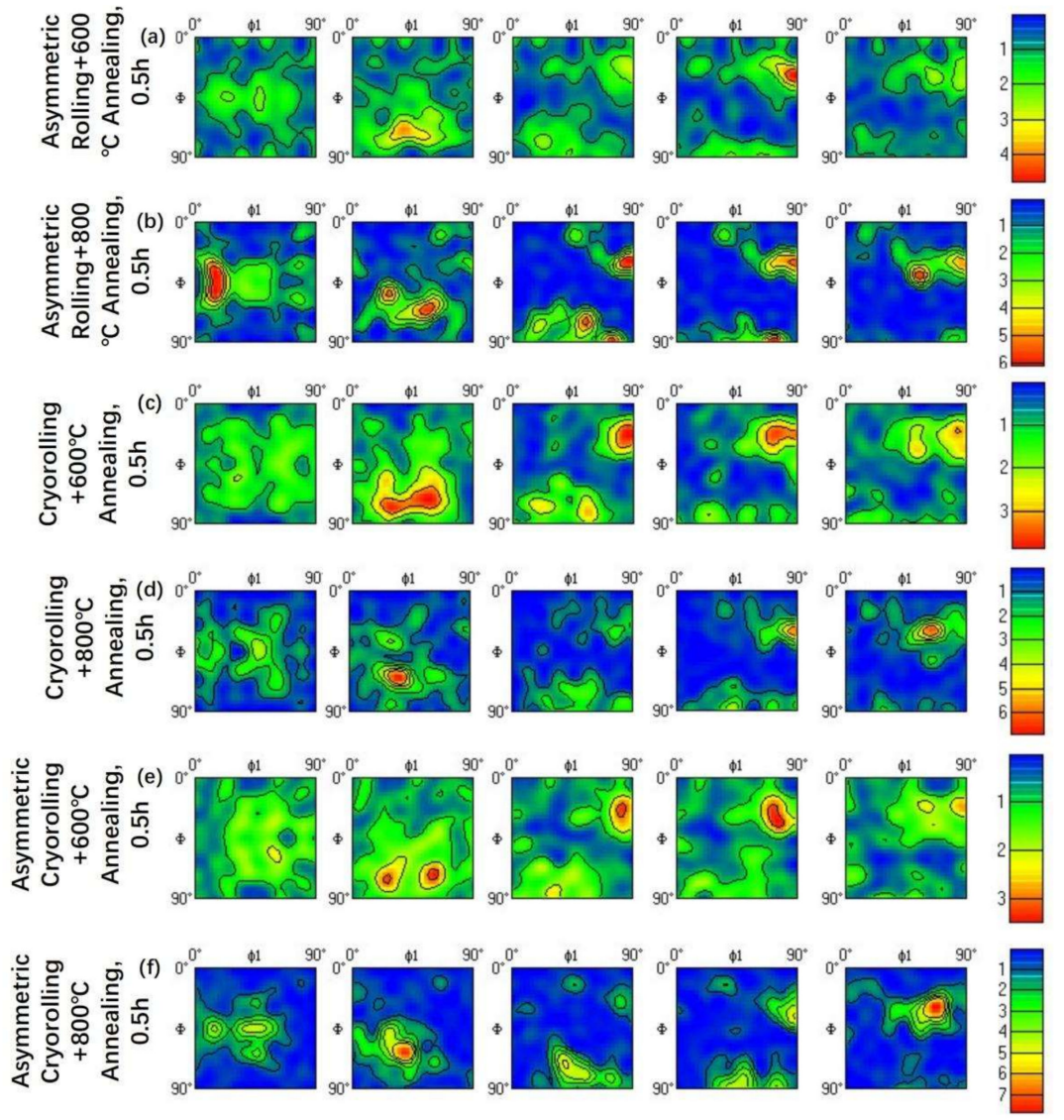

Figure 4. ODFs $\left(\phi_{2}=0^{\circ}, 15^{\circ}, 35^{\circ}, 45^{\circ}\right.$, and $65^{\circ}$ sections) sections of (a) asymmetrically rolled $\mathrm{CoCrNi}$ MEA with annealing at $600{ }^{\circ} \mathrm{C},(\mathrm{b})$ asymmetrically rolled CoCrNi MEA with annealing at $800{ }^{\circ} \mathrm{C}$, (c) cryorolled CoCrNi MEA with annealing at $600{ }^{\circ} \mathrm{C}$, (d) cryorolled MEA CrCoNi with annealing at $800{ }^{\circ} \mathrm{C}$, (e) asymmetric cryorolled $\mathrm{CoCrNi}$ MEA with annealing at $600^{\circ} \mathrm{C}$, and (f) asymmetric cryorolled CoCrNi MEA with annealing at $800{ }^{\circ} \mathrm{C}$.

The change in texture composition of the equiatomic CoCrNi alloy after asymmetric rolling, cryorolling, and asymmetric cryorolling followed by annealing at different temperatures is displayed in Figure $5 \mathrm{a}-\mathrm{c}$. The asymmetric rolled and annealed samples showed stronger random components compared to symmetric rolled and annealed CoCrNi MEA. In Figure 5, the random component was expressed as R (sum of volume fraction of components other than those shown in Table 1). The total volume fraction of the $\alpha$-fiber (the sum of the volume fractions of the components along the $\alpha$-fiber, namely G, G/B, BS, G/B(T) and Rt-G, in Figure 5, the $\alpha$-fiber was expressed as $\alpha$ ) did not exhibit significant changes and each texture component showed only a slight change with the annealing 
temperature. It is consistent with the results from the ODF sections in Figure 4. Haase et al. [50] reported that the main influence mechanism of texture randomization was the formation of twins during annealing, and the retention of deformation texture components in the recrystallization texture was mainly due to the nucleation of new grains at the grain boundary closed to the parent grains. Figure $5 \mathrm{~d}$ depicts the change in texture index (characterizing texture intensity) with the annealing temperature. It can be seen in Figure 5d that in the CoCrNi MEA under any rolling process, the texture index increases with an increase in annealing temperature, corresponding to the ODF sections of Figure 4, it was also observed that the MEA annealed at $800{ }^{\circ} \mathrm{C}$ had stronger texture components. It is in agreement with the research results of the cold-rolled and annealed CoCrFeMnNi high entropy alloy [41].
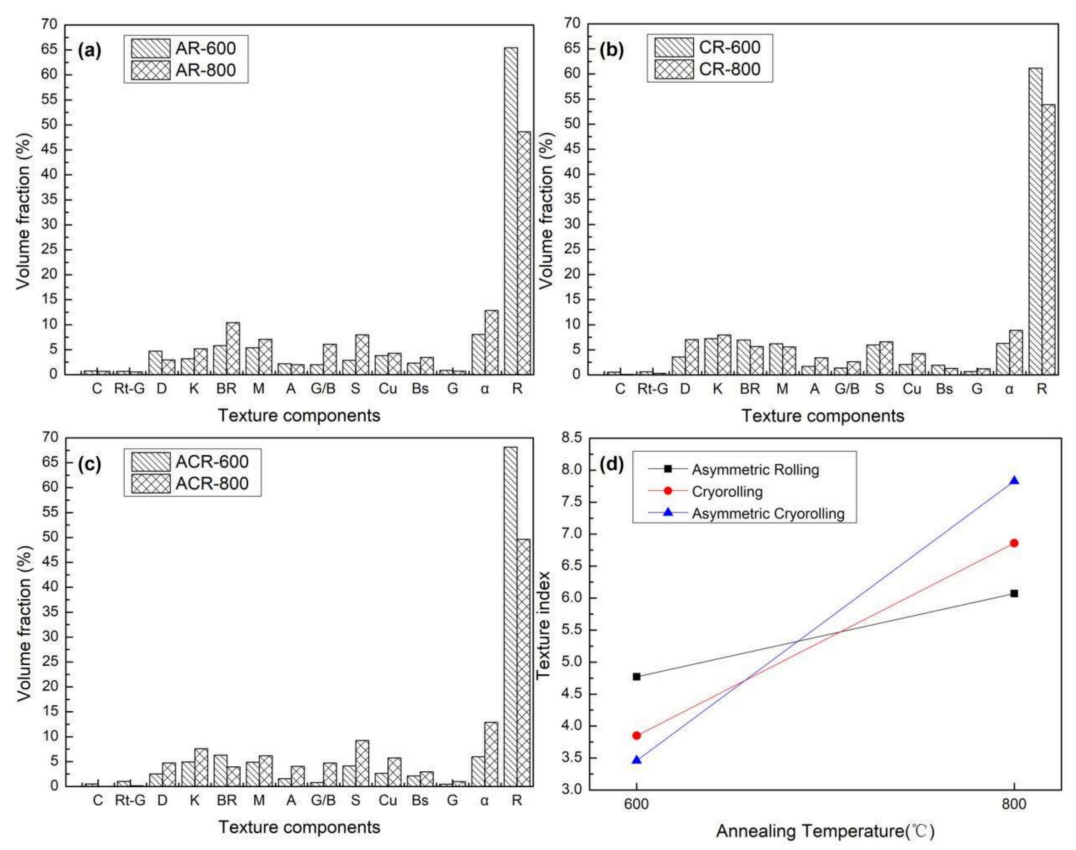

Figure 5. Variation of texture components with annealing temperature in (a) asymmetrically rolled CoCrNi MEA, (b) cryorolled CoCrNi MEA (c) asymmetric cryorolled CoCrNi MEA; (d) comparison of the variation of texture index with annealing temperature between asymmetrically rolled, cryorolled and asymmetric cryorolled CoCrNi MEA.

Figure 6 shows the microhardness variation with the rolling and annealing conditions, plotting the hardness as a function of rolling process methods. It evident that the hardness obtained after cryorolling is higher than that after asymmetric rolling, while the hardness of the MEA obtained by asymmetric cryorolling is higher than the both. The difference between the hardness obtained after cryorolling and asymmetric cryorolling is relatively small, and they are significantly higher than the hardness obtained after asymmetric rolling. This is also consistent with the previous analysis of the grain size distribution about Figure 2. The overall average grain size of the cryorolling material is significantly smaller. These results suggest that deformation temperature has a larger contribution to the mechanical strength improvement of our studied MEA, compared to the shear strain introduced by asymmetric rolling. According to previous studies [51-54], it has been proven that dislocation density and deformed microstructure is greatly affected by the deformation temperature for various metallic materials. The suppression of dynamic recovery by cryogenic deformation temperature leads to high defect density, which brings more potential nucleation sites during annealing and leads to finer grains [26]. The similar phenomenon has also been obtained in the current study. Moreover, the difference in hardness caused by different rolling process methods are almost kept even when annealing temperature is less than $700{ }^{\circ} \mathrm{C}$. When annealing temperature reaches $800^{\circ} \mathrm{C}$, the hardness of asymmetric cryorolling 
deformed MEA is obviously higher than the other two. Corresponding to Figure 1, it can be seen that the large-scale grains of asymmetric cryorolling was smaller than of asymmetric rolling. Meanwhile, the size of the small-grain of the asymmetric cryorolled CoCrNi MEA was obviously finer, compared with the MEAs obtained by other two processes. This showed that the asymmetric cryorolled deformed MEA after high temperature annealing had better thermal stability. This similar phenomenon has also been observed in previous studies on cryorolling, asymmetric rolling and asymmetric cryorolling [29], and this issue will be further studied in the future.
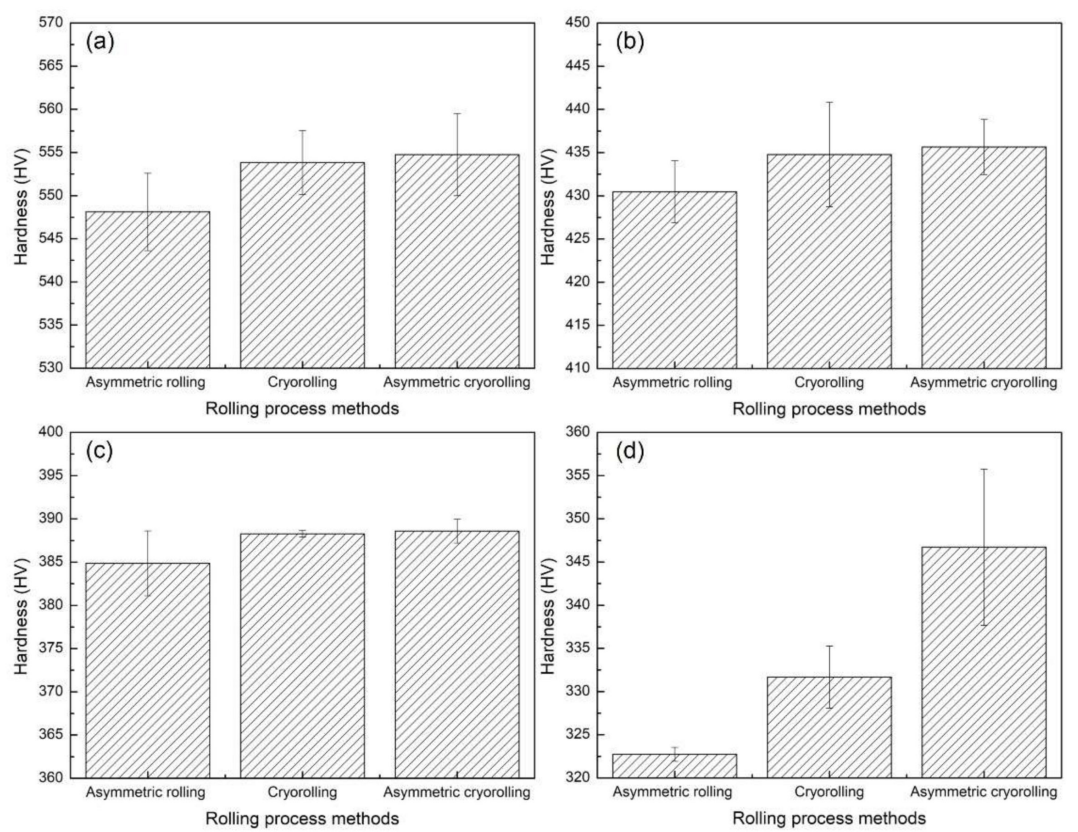

Figure 6. The hardness change diagram of the CoCrNi MEA (a) after asymmetric rolling, cryorolling, asymmetric cryorolling, and subsequent annealing at (b) $600{ }^{\circ} \mathrm{C}$, (c) $700{ }^{\circ} \mathrm{C}$, (d) $800{ }^{\circ} \mathrm{C}$.

\section{Conclusions}

The evolution of the texture and microstructure of the equiatomic medium entropy CoCrNi alloy after cryorolling, asymmetric rolling, and asymmetric cryorolling followed by subsequent annealing was investigated in the present work. Based on the research results, the following conclusions are drawn:

(1) As the annealing temperature increases, the $\sum 3$ grain boundaries gradually becomes straight from curve. The grain sizes of the annealed samples were mostly in the sub-micron. After high temperature annealing, the ultra-fine grain structure with an average size in the micron level were still maintained. The CoCrNi MEA after cryorolling and subsequent annealing had a high proportion of ultra-fine $(0-0.25 \mu \mathrm{m})$ grain size distribution and the upper limit of grain size was lower, compared with other rolled sample. Meanwhile, the asymmetrically rolled and annealed samples had an obvious two-stage grain size distribution. Asymmetrically cryorolled samples still remained heterogeneous grain size characteristics after high temperature annealing with finer small-grain and lower large-scale grain size.

(2) Annealed and recrystallized samples formed similar texture components and texture strength increased with increasing annealing temperature. After annealing, the $\alpha$-fiber textures such as $G$, $\mathrm{G} / \mathrm{B}, \mathrm{Bs}, \mathrm{A}$, and $\mathrm{S}$ textures were retained. A few orientations generated by annealing twinning were also observed. The asymmetric rolled and annealed samples exhibited stronger random components than symmetric rolled and annealed samples. The annealing temperature had little effect on the volume fraction of different texture components. 
(3) The hardness obtained after cryorolling and asymmetric cryorolling are similar, which are relatively higher than the hardness obtained after asymmetric rolling. It is mainly attributed to that deformation temperature has more significant effect on improving the mechanical properties, compared to the shear strain introduced by asymmetric rolling.

Author Contributions: Y.W.: Experiments, Investigation, Writing—original draft, review \& editing. J.L.: Investigation, Writing-review. L.B.: Investigation, Writing—review. C.K.: Experiments, Investigation, Writing-review \& editing. H.Y.: Conceptualization, Writing-review \& editing, Supervision. All authors have read and agreed to the published version of the manuscript.

Funding: This research was funded by National Key Research and Development Program (Grant No. 2019YFB2006500), the National Natural Science Foundation of China (Grant number: 51674303), Innovation Driven Program of Central South University (Grant number: 2019CX006), and the Research Fund of the Key Laboratory of High Performance Complex Manufacturing at Central South University.

Conflicts of Interest: The authors declare no conflict of interest.

\section{References}

1. Yeh, J.W.; Chen, S.K.; Lin, S.J.; Gan, J.Y.; Chin, T.S.; Shun, T.T.; Tsau, C.H.; Chang, S.Y. Nanostructured high-entropy alloys with multiple principal elements: Novel alloy design concepts and outcomes. Adv. Eng. Mater. 2004, 6, 299-303. [CrossRef]

2. Liang, Y.J.; Wang, L.; Wen, Y.; Cheng, B.; Wu, Q.; Cao, T.; Xiao, Q.; Xue, Y.; Sha, G.; Wang, Y.; et al. High-content ductile coherent nanoprecipitates achieve ultrastrong high-entropy alloys. Nat. Commun. 2018, 9, 4063. [CrossRef] [PubMed]

3. Huang, H.; Wang, J.; Yang, H.; Ji, S.; Yu, H.; Liu, Z. Strengthening CoCrNi medium-entropy alloy by tuning lattice defects. Scr. Mater. 2020, 188, 216-221. [CrossRef]

4. Du, X.H.; Li, W.P.; Chang, H.T.; Yang, T.; Duan, G.S.; Wu, B.L.; Huang, J.C.; Chen, F.R.; Liu, C.T.; Chuang, W.S.; et al. Dual heterogeneous structures lead to ultrahigh strength and uniform ductility in a Co-Cr-Ni medium-entropy alloy. Nat. Commun. 2020, 11, 2390. [CrossRef]

5. Wen, R.; You, C.; Zeng, L.; Wang, H.; Zhang, X. Achieving a unique combination of strength and ductility in CrCoNi medium-entropy alloy via heterogeneous gradient structure. J. Mater. Sci. 2020, 55, 12544-12553. [CrossRef]

6. Feng, X.; Yang, H.; Fan, R.; Zhang, W.; Meng, F.; Gan, B.; Lu, Y. Heavily twinned CoCrNi medium-entropy alloy with superior strength and crack resistance. Mater. Sci. Eng. A 2020, 788, 139591. [CrossRef]

7. Gludovatz, B.; Hohenwarter, A.; Catoor, D.; Chang, E.H.; George, E.P.; Ritchie, R.O. A fracture-resistant high-entropy alloy for cryogenic applications. Science 2014, 345, 1153-1158. [CrossRef]

8. Qian, C.; Li, K.; Guo, X.Y.; Liu, B.; Long, Z.Y.; Liu, Y. Effect of WC grain size on mechanical properties and microstructures of cemented carbide with medium entropy alloy Co-Ni-Fe binder. J. Cent. South Univ. 2020, 27, 1146-1157. [CrossRef]

9. Tang, Z.; Yuan, T.; Tsai, C.W.; Yeh, J.W.; Lundin, C.D.; Liaw, P.K. Fatigue behavior of a wrought $A 1_{0.5} \mathrm{CoCrCuFeNi}$ two-phase high-entropy alloy. Acta Mater. 2015, 99, 247-258. [CrossRef]

10. Chen, Y.Y.; Duval, T.; Hung, U.D.; Yeh, J.W.; Shih, H.C. Microstructure and electrochemical properties of high entropy alloys-A comparison with type-304 stainless steel. Corros. Sci. 2005, 47, 2257-2279. [CrossRef]

11. Xia, S.; Gao, M.C.; Yang, T.; Liaw, P.K.; Zhang, Y. Phase stability and microstructures of high entropy alloys ion irradiated to high doses. J. Nucl. Mater. 2016, 480, 100-108. [CrossRef]

12. Liu, J.P.; Chen, J.X.; Liu, T.W.; Li, C.; Chen, Y.; Dai, L.H. Superior strength-ductility CoCrNi medium-entropy alloy wire. Scr. Mater. 2020, 181, 19-24. [CrossRef]

13. Yeh, J.W. Alloy design strategies and future trends in high-entropy alloys. JOM 2013, 65, 1759-1771. [CrossRef]

14. Jian, W.R.; Xie, Z.; Xu, S.; Su, Y.; Yao, X.; Beyerlein, I.J. Effects of lattice distortion and chemical short-range order on the mechanisms of deformation in medium entropy alloy CoCrNi. Acta Mater. 2020, 199, 352-369. [CrossRef]

15. Kucza, W.; Dąbrowa, J.; Cieślak, G.; Berent, K.; Kulik, T.; Danielewski, M. Studies of "sluggish diffusion" effect in $\mathrm{Co}-\mathrm{Cr}-\mathrm{Fe}-\mathrm{Mn}-\mathrm{Ni}$, Co-Cr-Fe-Ni and $\mathrm{Co}-\mathrm{Fe}-\mathrm{Mn}-\mathrm{Ni}$ high entropy alloys; determination of tracer diffusivities by combinatorial approach. J. Alloy. Compd. 2018, 731, 920-928. [CrossRef] 
16. Wu, Z.; Bei, H.; Pharr, G.M.; George, E.P. Temperature dependence of the mechanical properties of equiatomic solid solution alloys with face-centered cubic crystal structures. Acta Mater. 2014, 81, 428-441. [CrossRef]

17. Laplanche, G.; Kostka, A.; Reinhart, C.; Hunfeld, J.; Eggeler, G.; George, E.P. Reasons for the superior mechanical properties of medium-entropy $\mathrm{CrCoNi}$ compared to high-entropy CrMnFeCoNi. Acta Mater. 2017, 128, 292-303. [CrossRef]

18. Sathiyamoorthi, P.; Bae, J.W.; Asghari-Rad, P.; Park, J.M.; Kim, J.G.; Kim, H.S. Effect of annealing on microstructure and tensile behavior of CoCrNi medium entropy alloy processed by high-pressure torsion. Entropy 2018, 20, 849. [CrossRef]

19. Ma, Y.; Yuan, F.; Yang, M.; Jiang, P.; Ma, E.; Wu, X. Dynamic shear deformation of a CrCoNi medium-entropy alloy with heterogeneous grain structures. Acta Mater. 2018, 148, 407-418. [CrossRef]

20. Yang, M.; Yan, D.; Yuan, F.; Jiang, P.; Ma, E.; Wu, X. Dynamically reinforced heterogeneous grain structure prolongs ductility in a medium-entropy alloy with gigapascal yield strength. Proc. Natl. Acad. Sci. USA 2018, 115, 7224-7229. [CrossRef]

21. Huang, H.; Li, X.; Dong, Z.; Li, W.; Huang, S.; Meng, D.; Lai, X.; Liu, T.; Zhu, S.; Vitos, L. Critical stress for twinning nucleation in CrCoNi-based medium and high entropy alloys. Acta Mater. 2018, 149, 388-396. [CrossRef]

22. Jo, Y.H.; Jung, S.; Choi, W.M.; Sohn, S.S.; Kim, H.S.; Lee, B.J.; Kim, N.J.; Lee, S. Cryogenic strength improvement by utilizing room-temperature deformation twinning in a partially recrystallized VCrMnFeCoNi high-entropy alloy. Nat. Commun. 2017, 8, 15719. [CrossRef] [PubMed]

23. Slone, C.E.; Chakraborty, S.; Miao, J.; George, E.P.; Mills, M.J.; Niezgoda, S.R. Influence of deformation induced nanoscale twinning and FCC-HCP transformation on hardening and texture development in medium-entropy CrCoNi alloy. Acta Mater. 2018, 158, 38-52. [CrossRef]

24. Wu, Z.; Parish, C.M.; Bei, H. Nano-twin mediated plasticity in carbon-containing FeNiCoCrMn high entropy alloys. J. Alloy. Compd. 2015, 647, 815-822. [CrossRef]

25. Won, J.W.; Lee, S.; Park, S.H.; Kang, M.; Lim, K.R.; Park, C.H.; Na, Y.S. Ultrafine-grained CoCrFeMnNi high-entropy alloy produced by cryogenic multi-pass caliber rolling. J. Alloy Compd. 2018, 742, 290-295. [CrossRef]

26. Yu, H.; Lu, C.; Tieu, A.K.; Li, H.J.; Godbole, A.; Zhang, S. Special rolling techniques for improvement of mechanical properties of ultrafine-grained metal sheets: A review. Adv. Eng. Mater. 2016, 18, 754-769. [CrossRef]

27. Shi, J.T.; Hou, L.G.; Ma, C.Q.; Zuo, J.R.; Cui, H.; Zhuang, L.Z.; Zhang, J.S. Mechanical properties and microstructures of $5052 \mathrm{Al}$ alloy processed by asymmetric cryorolling. Mater. Sci. Forum 2016, 850, 823-828. [CrossRef]

28. Yu, H.; Tieu, K.; Lu, C.; Lou, Y.; Liu, X.; Godbole, A.; Kong, C. Tensile fracture of ultrafine grained aluminum 6061 sheets by asymmetric cryorolling for microforming. Int. J. Damage Mech. 2014, 23, 1077-1095. [CrossRef]

29. Yu, H.; Wang, L.; Chai, L.; Li, J.; Lu, C.; Godbole, A.; Wang, H.; Kong, C. High thermal stability and excellent mechanical properties of ultrafine-grained high-purity copper sheets subjected to asymmetric cryorolling. Mater. Charact. 2019, 153, 34-45. [CrossRef]

30. Yu, H.; Du, Q.; Godbole, A.; Lu, C.; Kong, C. Improvement in strength and ductility of asymmetric-cryorolled copper sheets under low-temperature annealing. Metall. Mater. Trans. A 2018, 49, 4398-4403. [CrossRef]

31. Yu, H.; Lu, C.; Tieu, A.K.; Li, H.; Godbole, A.; Kong, C.; Zhao, X. Simultaneous grain growth and grain refinement in bulk ultrafine-grained copper under tensile deformation at room temperature. Metall. Mater. Trans. A 2016, 47, 3785-3789. [CrossRef]

32. Zhang, Z.; Wu, Y.; Bhatta, L.; Li, C.; Gan, B.; Kong, C.; Wang, Y.; Yu, H. Mechanical properties and microstructure evolution of a CrCoNi medium entropy alloy subjected to asymmetric cryorolling and subsequent annealing. Mater. Today Commun. 2020. [CrossRef]

33. Wu, Y.; Zhang, Z.; Liu, J.; Kong, C.; Wang, Y.; Tandon, P.; Pesin, A.; Zhilyaev, A.P.; Yu, H. Superior strengthening effect on heterogeneous lamellar structure in medium entropy alloy CrCoNi processed by asymmetric cryorolling. Under reviewing.

34. Okamoto, N.L.; Fujimoto, S.; Kambara, Y.; Kawamura, M.; Chen, Z.M.T.; Matsunoshita, H.; Tanaka, K.; Inui, H.; George, E.P. Size effect, critical resolved shear stress, stacking fault energy, and solid solution strengthening in the CrMnFeCoNi high-entropy alloy. Sci. Rep. 2016, 6, 35863. [CrossRef] [PubMed] 
35. Zhao, Y.L.; Yang, T.; Tong, Y.; Wang, J.; Luan, J.H.; Jiao, Z.B.; Chen, D.; Yang, Y.; Hu, A.; Liu, C.T.; et al. Heterogeneous precipitation behavior and stacking-fault-mediated deformation in a CoCrNi-based medium-entropy alloy. Acta Mater. 2017, 138, 72-82. [CrossRef]

36. Tang, Q.; Cai, X.; Dai, P. Grain boundary character distribution in CoCrFeMnNi high-entropy alloy after cold rolling and subsequent annealing. Heat Treat. Met. 2016, 41, 217-221.

37. Thomson, C.B.; Randle, V. “Fine tuning” at $\Sigma 3^{\mathrm{n}}$ boundaries in nickel. Acta Mater. 1997, 45, 4909-4916. [CrossRef]

38. Randle, V. Mechanism of twinning-induced grain boundary engineering in low stacking-fault energy materials. Acta Mater. 1999, 47, 4187-4196. [CrossRef]

39. Dan Sathiaraj, G.; Skrotzki, W.; Pukenas, A.; Schaarschuch, R.; Jose Immanuel, R.; Panigrahi, S.K.; Arout Chelvane, J.; Satheesh Kumar, S.S. Effect of annealing on the microstructure and texture of cold rolled CrCoNi medium-entropy alloy. Intermetallics 2018, 101, 87-98. [CrossRef]

40. Beke, D.L.; Erdélyi, G. On the diffusion in high-entropy alloys. Mater. Lett. 2016, 164, 111-113. [CrossRef]

41. Sathiaraj, G.D.; Bhattacharjee, P.P.; Tsai, C.W.; Yeh, J.W. Effect of heavy cryo-rolling on the evolution of microstructure and texture during annealing of equiatomic CoCrFeMnNi high entropy alloy. Intermetallics 2016, 69, 1-9. [CrossRef]

42. Sathiaraj, G.D.; Bhattacharjee, P.P. Effect of cold-rolling strain on the evolution of annealing texture of equiatomic CoCrFeMnNi high entropy alloy. Mater. Charact. 2015, 109, 189-197. [CrossRef]

43. Bhattacharjee, P.P.; Sathiaraj, G.D.; Zaid, M.; Gatti, J.R.; Lee, C.; Tsai, C.W.; Yeh, J.W. Microstructure and texture evolution during annealing of equiatomic CoCrFeMnNi high-entropy alloy. J. Alloy. Compd. 2014, 587, 544-552. [CrossRef]

44. Sathiaraj, G.D.; Ahmed, M.Z.; Bhattacharjee, P.P. Microstructure and texture of heavily cold-rolled and annealed fcc equiatomic medium to high entropy alloys. J. Alloy. Compd. 2016, 664, 109-119. [CrossRef]

45. Sathiaraj, G.D.; Lee, C.; Tsai, C.W.; Yeh, J.W.; Bhattacharjee, P.P. Evolution of microstructure and crystallographic texture in severely cold rolled high entropy equiatomic $\mathrm{CoCrFeMnNi}$ alloy during annealing. IOP Conf. Ser. Mater. Sci. Eng. 2015, 82, 012068. [CrossRef]

46. Jia, N.; Eisenlohr, P.; Roters, F.; Raabe, D.; Zhao, X. Orientation dependence of shear banding in face-centered-cubic single crystals. Acta Mater. 2012, 60, 3415-3434. [CrossRef]

47. Sathiaraj, G.D.; Bhattacharjee, P.P. Effect of starting grain size on the evolution of microstructure and texture during thermo-mechanical processing of CoCrFeMnNi high entropy alloy. J. Alloy. Compd. 2015, 647, 82-96. [CrossRef]

48. Tsai, K.Y.; Tsai, M.H.; Yeh, J.W. Sluggish diffusion in Co-Cr-Fe-Mn-Ni high-entropy alloys. Acta Mater. 2013, 61, 4887-4897. [CrossRef]

49. Sathiaraj, G.D.; Pukenas, A.; Skrotzki, W. Texture formation in face-centered cubic high-entropy alloys. J. Alloy. Compd. 2020, 826, 154183. [CrossRef]

50. Haase, C.; Barrales-Mora, L.A. Influence of deformation and annealing twinning on the microstructure and texture evolution of face-centered cubic high-entropy alloys. Acta Mater. 2018, 150, 88-103. [CrossRef]

51. Shi, Y.; Li, M.; Guo, D.; Ma, T.; Zhang, Z.; Li, X.; Zhang, G.; Zhang, X. Extraordinary toughening by cryorolling in Zr. Adv. Eng. Mater. 2014, 16, 167-170. [CrossRef]

52. D'yakonov, G.S.; Zherebtsov, S.V.; Klimova, M.V.; Salishchev, G.A. Microstructure evolution of commercialpurity titanium during cryorolling. Phys. Met. Metall. 2015, 116, 182-188. [CrossRef]

53. Yu, H.; Yan, M.; Li, J.; Godbole, A.; Lu, C.; Tieu, K.; Li, H.; Kong, C. Mechanical properties and microstructure of a Ti-6Al-4V alloy subjected to cold rolling, asymmetric rolling and asymmetric cryorolling. Mater. Sci. Eng. A 2018, 710, 10-16. [CrossRef]

54. Liu, J.; Wu, Y.; Wang, L.; Wang, H.; Kong, C.; Pesin, A.; Zhilyaev, A.P.; Yu, H. Fabrication and Characterization of High-Bonding-Strength Al/Ti/Al-Laminated Composites via Cryorolling. Acta Metall. Sin. Engl. Lett. 2020, 33, 871-880. [CrossRef]

Publisher's Note: MDPI stays neutral with regard to jurisdictional claims in published maps and institutional affiliations. 